\title{
Effect of products affecting soil fertility and plant resistance on the number of phytophagous insects in winter wheat crop fertilized with straw
}

\author{
Wpływ stosowania środków kształtujących żyzność gleby \\ i odporność roślin na liczebność fitofagicznej entomofauny \\ w uprawie pszenicy ozimej nawożonej słomą
}

\author{
Robert Lamparski ${ }^{1 *}$, Karol Kotwica ${ }^{2}$, Iwona Jaskulska ${ }^{2}$, Mariusz Piekarczyk ${ }^{2}$
}

\begin{abstract}
Summary
The aim of the study was the entomological observation in short-term monocultures of winter wheat at Sobiejuchy near Bydgoszcz in 2010 and 2011. Insects were collected with an entomological net three times during the growing seasons. In each of three replications of the treatment with an area of $24 \mathrm{~m}^{2}$, twelve sweeps were made. We found that products inducing soil fertility and an application of biostymulator in winter wheat fertilized with straw affected the numbers of phytophagous insects in different ways. When the effective microorganisms were applied, Oulema melanopus (L.) adults and Aelia acuminate (L.) at earing stage of winter wheat, Rhopalosiphum padi (L.), A. acuminate (L.) and O. cyanella (Voet.) adults at flowering stage and Sitobion avenae (F) H.R.L., A. acuminate (L.), Haplothrips aculeatus (Fabricius) and Frankiniella intonsa (Tybom) at milk-dough maturity were less numerous. The wheat pests occurring the most numerously at individual growth stages were significantly controlled with all applied products. However, none of the products decreased significantly an occurrence of $H$. aculeatus and $F$. intonsa at earning and flowering of winter wheat.
\end{abstract}

Key words: insects; winter wheat; biopreparations; $\mathrm{CaO}$; ash

\section{Streszczenie}

Obserwacje entomologiczne prowadzono w latach 2010 i 2011, w krótkotrwałej monokulturze pszenicy ozimej, w Sobiejuchach koło Bydgoszczy. Owady do badań pobierano wykorzystując czerpak entomologiczny. W każdym z trzech powtórzeń obiektu o powierzchni $24 \mathrm{~m}^{2}$ wykonano po 12 uderzeń. Badane środki kształtujące żyzność gleby i biostymulator wzrostu roślin wpłynęły w zróżnicowany sposób na liczebność fitofagicznej entomofauny w uprawie pszenicy ozimej nawożonej słomą. Stosowanie szczepionki EM-A najskuteczniej ograniczało liczebność odławianych osobników dorosłych skrzypionki zbożowej i lednicy zbożowej w fazie kłoszenia; mszycy czeremchowo-zbożowej, lednicy zbożowej i skrzypionki błękitek w fazie kwitnienia oraz mszycy zbożowej, lednicy oraz wciornastków kwiatowca i zbożowego w fazie dojrzałości mleczno-woskowej. Najliczniej występujące szkodniki w poszczególnych fazach rozwojowych pszenicy ozimej były istotnie ograniczane przez wszystkie zastosowane środki, natomiast żaden z nich nie zmniejszył istotnie występowania wciornastka kwiatowca i zbożowego w fazach kłoszenia oraz kwitnienia pszenicy ozimej.

Słowa kluczowe: owady; pszenica ozima; biopreparaty; CaO; popiół

\footnotetext{
Uniwersytet Technologiczno-Przyrodniczy w Bydgoszczy

Kordeckiego 20, 85-225 Bydgoszcz

${ }^{1}$ Katedra Entomologii i Fitopatologii Molekularnej

*corresponding author: robert@utp.edu.pl

${ }^{2}$ Katedra Podstaw Produkcji Roślinnej i Doświadczalnictwa
} 


\section{Wstęp / Introduction}

Wzrost, rozwój oraz plonowanie pszenicy uprawianej w monokulturze, zwłaszcza przy corocznym przyorywaniu słomy, podlegają silnej presji biotycznych i abiotycznych czynników stresowych. Założenia rolnictwa zrównoważonego zmuszają do poszukiwania proekologicznych sposobów ich ograniczania, których zadaniem jest zwiększanie różnorodności i aktywności mikroorganizmów glebowych, stabilizacja korzystnych właściwości fizykochemicznych gleby, neutralizacja związków toksycznych, a także stymulowanie mechanizmów odporności roślin na stresy środowiskowe (Gajewski i wsp. 2010; Kotwica i wsp. 2011; Matysiak i wsp. 2011; Kordas i Zbroszczyk 2012). W warunkach narastającego niedoboru obornika, słoma staje się podstawowym prekursorem trwałej materii organicznej w glebie, źródłem energii dla mikroorganizmów oraz wpływa na jej właściwości fizykochemiczne (Malicki 1997; Jaskulski i Jaskulska 2004). Jednak ze względu na uwalnianie w trakcie rozkładu słomy związków biologicznie aktywnych oraz niebezpieczeństwo pogorszenia stanu fitosanitarnego gleby, traktowanie jej jako elementu regenerującego stanowisko w monokulturach zbożowych jest dyskusyjne (Smagacz i Sowiński 2005; Kotwica i wsp. 2011).

Słabo rozpoznany wpływ wielu zabiegów kształtujących żyzność gleby i biostymulatorów wzrostu roślin na skład jakościowo-ilościowy fauny zasiedlającej ich łany utrudnia ocenę skuteczności tych zabiegów zarówno w profilaktyce, jak i w bezpośrednim ograniczaniu występowania szkodników roślin uprawnych (Lamparski i Szczepanek 2013; Lamparski i wsp. 2013).

Celem badań było określenie wpływu stosowania środków kształtujących żyzność gleby i biostymulatora wzrostu roślin Asahi SL na liczebność fitofagicznej ento- mofauny w krótkotrwałej monokulturze pszenicy ozimej nawożonej słomą.

\section{Materiały i metody / Materials and methods}

Obserwacje entomologiczne prowadzono na pszenicy ozimej w latach 2010-2011, na obiektach doświadczenia polowego realizowanego w Zakładzie Nasienno-Rolnym Sobiejuchy, należącym do firmy DANKO Hodowla Roślin Sp. z o.o. w Choryni, w ramach projektu PB-0834/B/P01/ 2009/36 finansowanego przez Ministerstwo Nauki i Szkolnictwa Wyższego (tab. 1).

Pszenicę ozimą odmiany Leiffer uprawiano na glebie kompleksu żytniego bardzo dobrego, klasy bonitacyjnej IIIb, w monokulturze od 2008 roku. Corocznie po zbiorze przedplonu wnoszono do gleby rozdrobnioną słomę. Nawożenie fosforowo-potasowe, wynikające z zasobności gleby, stosowano przedsiewnie w dawkach $36 \mathrm{~kg} / \mathrm{ha} \mathrm{P}_{2} \mathrm{O}_{5}$ i $66 \mathrm{~kg} / \mathrm{ha} \mathrm{K}_{2} \mathrm{O}$, a azot - $140 \mathrm{~kg} / \mathrm{ha} \mathrm{N}$ wiosną w 3 dawkach $(60 \mathrm{~kg} / \mathrm{ha} \mathrm{N}$ w momencie ruszania wegetacji, $60 \mathrm{~kg} / \mathrm{ha} \mathrm{N}$ w fazie BBCH 32-33, $20 \mathrm{~kg} / \mathrm{ha} \mathrm{N}$ w fazie BBCH 54-56). Ziarno zaprawione zaprawą Maxim Star (substancja czynna - s.cz. cyprokonazol + difluorobenzol) w dawce $200 \mathrm{~g}$ preparatu/100 kg wysiewano w gęstości $450 \mathrm{szt} . / \mathrm{m}^{2}$. Chwasty zwalczano jesienią mieszaniną herbicydów Cougar $600 \mathrm{SC}$ (s.cz. diflufenikan + izoproturon) + Glean 75 WG (s.cz. chlorosulfuron), w dawkach odpowiednio $1,35 \mathrm{l} /$ ha i $6 \mathrm{~g} /$ ha. Wiosna w fazie BBCH 32 zastosowano mieszaninę regulatorów wzrostu: Antywylegacz $750 \mathrm{SL}$ (s.cz. chlorek chlormekwatu) i Moddus 250 EC (s.cz. trineksapak etylu) w dawkach odpowiednio 1,0 i 0,3 1/ha. Zabieg połączono z aplikacją fungicydu Capalo 337,5 SL (s.cz. epoksykonazol + fenpropimorf + metrafenon) w dawce 1,5 1/ha. Ochrony insektycydowej nie stosowano.

Tabela 1. Obiekty doświadczenia, dawki i sposób aplikacji środków wpływających na żyzność gleby oraz biostymulatora wzrostu roślin Table 1. Experimental objects, rates and the method of application of agents affecting the soil fertility and biostimulator of plant growth

\begin{tabular}{|c|c|c|}
\hline Obiekt-Object & Dawka - Rate & Sposób aplikacji - Application method \\
\hline $\begin{array}{l}\text { Kontrola } \\
\text { Control }\end{array}$ & \multicolumn{2}{|c|}{$\begin{array}{l}\text { rozdrobniona słoma przedplonu mieszana } \mathrm{z} \text { gleba w trakcie uprawy pożniwnej } \\
\text { shredded forecrop straw mixed with soil during post-harvest cultivation }\end{array}$} \\
\hline $\begin{array}{l}\text { Popió }^{*} \\
\text { Ash }^{*}\end{array}$ & $5,0 \mathrm{dt} / \mathrm{ha}$ & $\begin{array}{l}\text { na rozdrobnioną słomę przedplonu i wymieszany } \\
\text { z glebą w trakcie uprawy pożniwnej } \\
\text { on shredded forecrop straw and mixed with soil } \\
\text { during post-harvest cultivation }\end{array}$ \\
\hline $\mathrm{CaO}$ & $15,0 \mathrm{dt} / \mathrm{ha}$ & jw. - as above \\
\hline $\begin{array}{l}\text { Użyźniacz } \mathrm{UG}_{\max } \\
\text { Fertility booster } \mathrm{UG}_{\max }\end{array}$ & 0,9 1/ha & jw. - as above \\
\hline $\begin{array}{l}\text { Szczepionka EM-A } \\
\text { Vaccine EM-A }\end{array}$ & $\begin{array}{c}5,0 \text { l/ha } \\
\text { tj. } 100 \text { 1/ha EM-A } \\
\text { namely } 100 \text { 1/ha EM-A }\end{array}$ & jw. - as above \\
\hline $\begin{array}{l}\text { Biostymulator Asahi SL } \\
\text { Biostimulator }\end{array}$ & $0,61 / \mathrm{ha}$ & $\begin{array}{l}\text { dwukrotnie, każdorazowo po } 50 \% \text { dawki całkowitej } \\
\text { po wznowieniu wiosennej wegetacji } \\
\text { i w fazie liścia flagowego (BBCH } 39 \text { ) } \\
\text { twice, each time } 50 \% \text { of the total rate after resuming spring } \\
\text { vegetation and at the flag leaf phase (BBCH 39) }\end{array}$ \\
\hline
\end{tabular}

\footnotetext{
* popiół ze słomy jęczmienia jarego - spring barley straw ash: $\mathrm{pH}$ - 10,0; $\mathrm{P}-20,7 \mathrm{~g} / \mathrm{kg} ; \mathrm{K}-247,3 \mathrm{~g} / \mathrm{kg} ; \mathrm{Mg}-5,2 \mathrm{~g} / \mathrm{kg} ; \mathrm{Ca}-80,1 \mathrm{~g} / \mathrm{kg} ; \mathrm{Cu}-31,3 \mathrm{mg} / \mathrm{kg}$; $\mathrm{Mn}-1035,8 \mathrm{mg} / \mathrm{kg} ; \mathrm{Zn}-289,2 \mathrm{mg} / \mathrm{kg} ; \mathrm{Fe}-2200 \mathrm{mg} / \mathrm{kg}$

** substancja biologicznie czynna - biologically active substance: para-nitrofenolan sodu - para-nitro sodium phenolate $-0,3 \%+$ orto-nitrofenolan sodu

- ortho-nitro sodium phenolate - 0,2\% + 5-nitroguajakolan sodu - sodium-5-nitro-guaiacolate - $0,1 \%$
} 
Odłów owadów prowadzono w fazie kłoszenia $(\mathrm{BBCH}$ 57-59), kwitnienia (BBCH 65-69) oraz dojrzałości mleczno-woskowej pszenicy (BBCH 77-83). W tym celu na poletkach o powierzchni $24 \mathrm{~m}^{2}$ wykonywano po 12 uderzeń czerpakiem entomologicznym $(32 \mathrm{~cm}$ średnica obręczy), w trzech powtórzeniach. Materiał entomologiczny oznaczono według kluczy: Müller (1976), Korcz (1994), Zawirska (1994) i Warchałowski (2003). Liczbę odłowionych osobników na poszczególnych obiektach doświadczalnych porównano statystycznie. Wykonano analizę wariancji, istotność różnic międzyobiektowych oceniono testem Tukeya na poziomie istotności $\mathrm{p}=0,05$.

\section{Wyniki i dyskusja / Results and discussion}

$\mathrm{Na}$ podstawie przeprowadzonych obserwacji stwierdzono, że stosowanie środków kształtujących żyzność gleby oraz biostymulatora wpłynęło istotnie na liczebność niektórych szkodników występujących w kolejnych fazach wzrostu i rozwoju pszenicy ozimej (tab. 2-4).

Tabela 2. Liczebność odłowu wybranych owadów w fazie kłoszenia pszenicy ozimej, w latach 2010-2011 [szt./poletko]

Table 2. Number of chosen insects caught at earing stage of winter wheat in 2010-2011 [individuals per plot]

\begin{tabular}{|c|c|c|c|c|c|}
\hline $\begin{array}{c}\text { Kontrola } \\
\text { Control }\end{array}$ & $\begin{array}{c}\text { Popiół } \\
\text { Ash }\end{array}$ & $\mathrm{CaO}$ & $\mathrm{UG}_{\max }$ & EM-A & Asahi \\
\hline \multicolumn{6}{|c|}{ Skrzypionka zbożowa - Oulema melanopus L. (imagines - adults) (Chrysomelidae) } \\
\hline $4,00 \mathrm{c}$ & $3,33 \mathrm{bc}$ & $2,67 \mathrm{ab}$ & $2,67 \mathrm{ab}$ & $1,83 \mathrm{a}$ & $2,00 \mathrm{a}$ \\
\hline \multicolumn{6}{|c|}{ Skrzypionka błękitek - Oulema cyanella Voet. (imagines - adults) (Chrysomelidae) } \\
\hline $0,83 \mathrm{ab}$ & $0,50 \mathrm{a}$ & $1,00 \mathrm{~b}$ & $0,50 \mathrm{a}$ & $0,50 \mathrm{a}$ & $0,67 \mathrm{ab}$ \\
\hline \multicolumn{6}{|c|}{ Mszyca zbożowa - Sitobion avenae (F.) H.R.L. (Aphididae) } \\
\hline $2,00 \mathrm{c}$ & $0,83 \mathrm{a}$ & $1,83 \mathrm{c}$ & $1,67 \mathrm{bc}$ & $2,00 \mathrm{c}$ & $1,17 \mathrm{ab}$ \\
\hline \multicolumn{6}{|c|}{ Mszyca czeremchowo-zbożowa - Rhopalosiphum padi L. (Aphididae) } \\
\hline $2,17 \mathrm{c}$ & $1,83 \mathrm{bc}$ & $1,17 \mathrm{ab}$ & $1,83 \mathrm{bc}$ & $1,50 \mathrm{abc}$ & $0,83 \mathrm{a}$ \\
\hline \multicolumn{6}{|c|}{ Lednica zbożowa - Aelia acuminate L. (Pentatomidae) } \\
\hline $6,33 \mathrm{c}$ & $4,17 \mathrm{~b}$ & $4,33 \mathrm{~b}$ & $4,67 \mathrm{~b}$ & $2,83 \mathrm{a}$ & $4,50 \mathrm{~b}$ \\
\hline \multicolumn{6}{|c|}{ Wciornastek kwiatowiec - Frankiniella intonsa Trybom (Thripidae) } \\
\hline 3,00 & 1,83 & 2,00 & 1,83 & 2,00 & 2,17 \\
\hline \multicolumn{6}{|c|}{ Wciornastek zęborogi - Limothrips denticornis Haliday (Thripidae) } \\
\hline $2,67 \mathrm{c}$ & $2,17 \mathrm{c}$ & $0,83 \mathrm{a}$ & $2,50 \mathrm{c}$ & $1,50 \mathrm{~b}$ & $0,83 \mathrm{a}$ \\
\hline \multicolumn{6}{|c|}{ Wciornastek zbożowy - Haplothripini aculeatus F. (Phlaeothripidae) } \\
\hline 1,17 & 1,17 & 0,50 & 1,00 & 1,33 & 0,83 \\
\hline
\end{tabular}

Wartości oznaczone tymi samymi literami nie różnią się istotnie przy $\mathrm{p}=0,05$ zgodnie $\mathrm{z}$ testem Tukeya

Values with the same letter are not significantly diferrent at $\mathrm{p}=0.05$ according to Tukey's test

Tabela 3. Liczebność odłowu wybranych owadów w fazie kwitnienia pszenicy ozimej, w latach 2010-2011 [szt./poletko]

Table 3. Number of chosen insects caught at flowering stage of winter wheat in 2010-2011 [individuals per plot]

\begin{tabular}{|c|c|c|c|c|c|}
\hline $\begin{array}{c}\text { Kontrola } \\
\text { Control }\end{array}$ & $\begin{array}{l}\text { Popiół } \\
\text { Ash }\end{array}$ & $\mathrm{CaO}$ & $\mathrm{UG}_{\max }$ & EM-A & Asahi \\
\hline 1 & 2 & 3 & 4 & 5 & 6 \\
\hline \multicolumn{6}{|c|}{ Skrzypionka zbożowa - Oulema melanopus L. (imagines - adults) (Chrysomelidae) } \\
\hline $5,17 \mathrm{~d}$ & $2,83 \mathrm{~b}$ & $1,33 \mathrm{a}$ & $2,33 \mathrm{~b}$ & $3,83 \mathrm{c}$ & $2,67 \mathrm{~b}$ \\
\hline \multicolumn{6}{|c|}{ Skrzypionka błękitek - Oulema cyanella Voet. (imagines - adults) (Chrysomelidae) } \\
\hline $1,33 \mathrm{~b}$ & $0,83 \mathrm{ab}$ & $0,67 \mathrm{ab}$ & $0,83 \mathrm{ab}$ & $0,50 \mathrm{a}$ & $0,67 \mathrm{ab}$ \\
\hline \multicolumn{6}{|c|}{ Larwy skrzypionek - Oulema spp. larvae } \\
\hline $3,83 \mathrm{~b}$ & $2,17 \mathrm{a}$ & $2,50 \mathrm{ab}$ & $2,67 \mathrm{ab}$ & $3,17 \mathrm{ab}$ & $2,00 \mathrm{a}$ \\
\hline \multicolumn{6}{|c|}{ Mszyca zbożowa - Sitobion avenae (F.) H.R.L. (Aphididae) } \\
\hline $7,33 \mathrm{c}$ & $5,00 \mathrm{~b}$ & $4,50 \mathrm{~b}$ & $2,67 \mathrm{a}$ & $4,17 \mathrm{ab}$ & $4,83 \mathrm{~b}$ \\
\hline \multicolumn{6}{|c|}{ Mszyca czeremchowo-zbożowa - Rhopalosiphum padi L. (Aphididae) } \\
\hline $1,83 \mathrm{~b}$ & $0,83 \mathrm{a}$ & $2,50 \mathrm{c}$ & $1,67 \mathrm{~b}$ & $0,83 \mathrm{a}$ & $1,83 \mathrm{~b}$ \\
\hline \multicolumn{6}{|c|}{ Lednica zbożowa - Aelia acuminate L. (Pentatomidae) } \\
\hline $2,67 \mathrm{c}$ & $2,67 \mathrm{c}$ & $2,00 \mathrm{bc}$ & $2,33 \mathrm{bc}$ & $1,17 \mathrm{a}$ & $1,67 \mathrm{ab}$ \\
\hline
\end{tabular}




\begin{tabular}{c|c|c|c|c|c}
\hline 1 & 2 & 3 & 4 & 5 & 6 \\
\hline \multicolumn{7}{c|}{ Wciornastek kwiatowiec - Frankiniella intonsa Trybom (Thripidae) } \\
\hline $2,33 \mathrm{ab}$ & $1,83 \mathrm{ab}$ & $2,00 \mathrm{ab}$ & $2,67 \mathrm{~b}$ & $1,33 \mathrm{a}$ & $2,00 \mathrm{ab}$ \\
\hline \multicolumn{7}{c}{ Wciornastek zęborogi - Limothrips denticornis Haliday (Thripidae) } \\
\hline $2,17 \mathrm{a}$ & $2,83 \mathrm{~b}$ & $2,00 \mathrm{a}$ & $3,17 \mathrm{~b}$ & $1,83 \mathrm{a}$ & $1,83 \mathrm{a}$ \\
\hline \multicolumn{7}{c}{ Wciornastek zbożowy - Haplothripini aculeatus $\mathrm{F}$. (Phlaeothripidae) } \\
\hline $1,50 \mathrm{ab}$ & $2,17 \mathrm{~b}$ & $1,00 \mathrm{a}$ & $1,33 \mathrm{a}$ & $1,50 \mathrm{ab}$ & $1,67 \mathrm{ab}$ \\
\hline
\end{tabular}

Wartości oznaczone tymi samymi literami nie różnią się istotnie przy $\mathrm{p}=0,05$ zgodnie $\mathrm{z}$ testem Tukeya

Values with the same letter are not significantly diferrent at $p=0.05$ according to Tukey's test

Tabela 4. Liczebność odłowu wybranych owadów w fazie dojrzałości mleczno-woskowej pszenicy ozimej, w latach 2010-2011 [szt./poletko]

Table 4. Number of chosen insects caught at milk-dough maturity stage of winter wheat in 2010-2011 [individuals per plot]

\begin{tabular}{c|c|c|c|c|c}
\hline $\begin{array}{c}\text { Kontrola } \\
\text { Control }\end{array}$ & $\begin{array}{c}\text { Popiół } \\
\text { Ash }\end{array}$ & CaO & UG $_{\max }$ & EM-A & Asahi \\
\hline \multicolumn{7}{c}{ Mszyca zbożowa - Sitobion avenae (F.) H.R.L. (Aphididae) } \\
\hline $33,00 \mathrm{~d}$ & $30,00 \mathrm{c}$ & $27,00 \mathrm{~b}$ & $26,83 \mathrm{~b}$ & $23,33 \mathrm{a}$ & $26,33 \mathrm{~b}$ \\
\hline \multicolumn{7}{c}{ Lednica zbożowa - Aelia acuminate L. (Pentatomidae) } \\
\hline $3,17 \mathrm{c}$ & $1,50 \mathrm{~b}$ & $1,33 \mathrm{a}$ & $2,00 \mathrm{~b}$ & $1,33 \mathrm{a}$ & $2,17 \mathrm{~b}$ \\
\hline \multicolumn{7}{c}{ Wciornastek kwiatowiec - Frankiniella intonsa Trybom (Thripidae) } \\
\hline \multicolumn{7}{c}{$1,83 \mathrm{bc}$} & $1,50 \mathrm{ab}$ & $1,17 \mathrm{a}$ & $2,33 \mathrm{~cd}$ \\
\hline \multicolumn{7}{c}{ Wciornastek zbożowy - Haplothripini aculeatus F. (Phlaeothripidae) } \\
\hline
\end{tabular}

Wartości oznaczone tymi samymi literami nie różnią się istotnie przy $\mathrm{p}=0,05$ zgodnie $\mathrm{z}$ testem Tukeya

Values with the same letter are not significantly diferrent at $\mathrm{p}=0.05$ according to Tukey's test

W fazie kłoszenia (BBCH 57-59) najliczniej występowała lednica zbożowa i skrzypionka zbożowa (tab. 2). Według Walczak (2007) szczególnie istotne dla zbóż w tej fazie rozwojowej jest występowanie skrzypionek. W badaniach własnych, stadium doskonałe skrzypionki zbożowej odławiano częściej niż skrzypionki błękitek. Ograniczająco w stosunku do liczby osobników skrzypionki zbożowej odławianych na obiekcie kontrolnym, wpłynęły wszystkie środki kształtujące żyzność gleby, z wyjątkiem popiołu ze słomy, a także biostymulator. Mniej osobników mszycy zbożowej stwierdzono na obiektach, gdzie stosowano popiół i biostymulator Asahi SL, mszycy czeremchowo-zbożowej po aplikacji tlenku wapnia i biostymulatora, wciornastka zęborogiego $-\mathrm{CaO}$, Asahi SL oraz szczepionki efektywnych mikroorganizmów EM-A, a lednicy zbożowej w wyniku użycia wszystkich środków. Na oddziaływanie biopreparatów ograniczające występowanie $O$. melanopus wskazują Lamparski i wsp. (2013).

W fazie kwitnienia (BBCH 65-69) pszenicy ozimej stwierdzono te same szkodniki, co $\mathrm{w}$ fazie kłoszenia i w porównywalnej liczebności, a ponadto larwy skrzypionek zbożowych (tab. 3). Analiza statystyczna wykazała, że stosowanie szczepionki EM-A najskuteczniej ograniczało występowanie stadium doskonałego skrzypionki błękitek, mszycy czeremchowo-zbożowej i lednicy zbożowej. Aplikacja biostymulatora Asahi SL zmniejszyła najbardziej liczebność larw skrzypionek zbożowych, a zastosowanie użyźniacza glebowego - mszycy zbożowej. Podobną skuteczność oddziaływania, zarówno EM-A, jak i biostymu- latora Asahi SL na fitofagiczną entomofaunę pszenicy ozimej, stwierdzili wcześniej Lamparski i wsp. (2013).

W fazie dojrzałości mleczno-woskowej (BBCH 77-83) pszenicy ozimej różnorodność gatunkowa szkodliwej entomofauny była mniejsza niż w fazach wcześniejszych (tab. 4). W tym okresie występowała głównie mszyca zbożowa, co jest zgodne $\mathrm{z}$ wynikami badań Hureja i wsp. (2009) oraz Lamparskiego i wsp. (2013). Mszyca ta wymieniana jest przez wielu badaczy jako najważniejszy gatunek wpływający na rozwój roślin zbożowych w końcowych fazach ich rozwoju (Żurańska i wsp. 1994; Lamparski i Szczepanek 2011).

Liczebność mszycy zbożowej $\mathrm{w}$ fazie dojrzałości mleczno-woskowej pszenicy ozimej, jak i pozostałych szkodników najbardziej ograniczała szczepionka efektywnych mikroorganizmów EM-A (tab. 4). Należy jednak podkreślić, że liczebność tego szkodnika oraz lednicy zbożowej na wszystkich obiektach, gdzie stosowano środki kształtujące żyzność gleby i biostymulator była istotnie mniejsza niż na obiekcie kontrolnym.

\section{Wnioski / Conclusions}

1. Środki kształtujące żyzność gleby i biostymulator Asahi SL stosowane w krótkotrwałej monokulturze pszenicy ozimej nawożonej słomą wpływały na liczebność fitofagicznej entomofauny.

2. Występowanie osobników doskonałych skrzypionki zbożowej i lednicy zbożowej w fazie kłoszenia mszycy czeremchowo-zbożowej, lednicy zbożowej i skrzy- 
pionki błękitek w fazie kwitnienia oraz szkodników pszenicy ozimej w fazie dojrzałości mleczno-woskowej najbardziej ograniczała szczepionka efektywnych mikroorganizmów EM-A.

3. Najliczniej występujące szkodniki w poszczególnych fazach rozwojowych pszenicy ozimej były istotnie ograniczane przez wszystkie zastosowane środki kształtujące żyzność gleby i biostymulator Asahi SL.

4. Żaden ze środków nie ograniczył istotnie występowania wciornastka kwiatowca i zbożowego w fazach kłoszenia oraz kwitnienia pszenicy ozimej.

\section{Literatura / References}

Gajewski P., Kaczmarek Z., Mrugalska L. 2010. Wpływ wzrastających dawek preparatu EM-A na właściwości gleb uprawnych. Cz. I. Właściwości fizyczne i wodne. Journal of Research and Applications in Agricultural Engineering 55 (3): 75-79.

Hurej M., Twardowski J., Pastuszko K., Chrzanowska-Drożdż B. 2009. Zagrożenie pszenicy twardej (Triticum durum Desf.) przez szkodliwą entomofaunę. [Threat of durum wheat (Triticum durum Desf.) with pest insects]. Progress in Plant Protection/Postępy w Ochronie Roślin 49 (4): 1697-1700.

Jaskulski D., Jaskulska I. 2004. Wpływ nawożenia słomą, międzyplonów ścierniskowych i zróżnicowanej uprawy roli na niektóre właściwości gleby w ogniwie pszenica ozima - jęczmień jary. Acta Scientiarum Polonorum, Agricultura 3 (2): $151-163$.

Korcz A. 1994. Szkodliwe pluskwiaki z rzędu różnoskrzydłych (Heteroptera). s. 233-292. W: „Diagnostyka szkodników roślin i ich wrogów naturalnych" (J. Boczek, red.). Szkoła Główna Gospodarstwa Wiejskiego, Warszawa, 327 ss.

Kordas L., Zbroszczyk U. 2012. Wpływ systemu uprawy roli i efektywnych mikroorganizmów (EM) na właściwości biologiczne gleby spod pszenicy jarej uprawianej w krótkotrwałej monokulturze. Fragmenta Agronomica 29 (3): 95-102.

Kotwica K., Jaskulska I., Jaskulski D., Gałęzewski L., Walczak D. 2011. Wpływ nawożenia azotem i sposobu użyźniania gleby na plonowanie pszenicy ozimej w zależności od przedplonu. Fragmenta Agronomica 28 (3): 53-63.

Lamparski R., Kotwica K., Jaskulski D., Piekarczyk M., Wawrzyniak M. 2013. Wpływ stosowania biopreparatów w uprawie pszenicy ozimej na liczebność fitofagicznej entomofauny. Fragmenta Agronomica 30 (3): 108-114.

Lamparski R., Szczepanek M. 2011. Hemiptero- i thysanopterofauna kostrzewy czerwonej (Festuca rubra L.) uprawianej na nasiona w zależności od sposobu siewu oraz odmiany. Fragmenta Agronomica 28 (1): 32-39.

Lamparski R., Szczepanek M. 2013. Wpływ stosowania bioregulatora Kelpak na występowanie fitofagów w pszenicy jarej. [Effect of bioregulator Kelpak application in spring wheat on the occurrence of phytophagous insects]. Progress in Plant Protection/Postępy w Ochronie Roślin 53 (1): 47-51.

Malicki L. 1997. Znaczenie resztek pożniwnych w płodozmianie. Acta Academiae Agriculturae Technicae Olstenensis, Agricultura 64: $57-66$.

Matysiak K., Adamczewski K., Kaczmarek S. 2011. Wpływ biostymulatora ASAHI SL na plonowanie i wybrane cechy ilościowe i jakościowe niektórych roślin rolniczych uprawianych w warunkach Wielkopolski. [Response of some crops cultivated in Great Poland to application of Asahi SL]. Progress in Plant Protection/Postępy w Ochronie Roślin 51 (4): 1849-1857.

Müller F.P. 1976. Mszyce - szkodniki roślin. PWN, Warszawa, 119 ss.

Smagacz J., Sowiński M. 2005. Porażenie przez patogeny podstawy źdźbła i plonowanie odmian pszenicy ozimej w zależności od częstotliwości przyorywania słomy. Biuletyn Instytutu Hodowli i Aklimatyzacji Roślin 235: 105-113.

Walczak F. 2007. Poradnik sygnalizatora ochrony zbóż. Instytut Ochrony Roślin, Poznań, 111 ss.

Warchałowski A. 2003. Chrysomelidae. The leaf v-beetles of Europe and the Mediterranean area. Natura Optima Dux, Warszawa, 600 ss.

Zawirska I. 1994. Wciornastki (Thysanoptera). s. 145-174. W: „Diagnostyka szkodników roślin i ich wrogów naturalnych” (J. Boczek, red.). Szkoła Główna Gospodarstwa Wiejskiego, Warszawa, 327 ss.

Żurańska I., Kordan B., Śledź D. 1994. Badania nad występowaniem mszyc (Homoptera, Aphididae) na trawach nasiennych. Polskie Pismo Entomologiczne 63 (3-4): 369-378. 